\title{
Implementing Best Practices and Facing Facilities Realities: Creation of a New University Makerspace
}

\author{
Madeleine F. Jennings, Texas State University
}

Madeleine Jennings is an undergraduate researcher at Texas State University studying Manufacturing Engineering. Her research interests include ferrous metallurgy, ferrous continuous casting process improvement, women and minority retention in STEM fields, and the effects and implications of university maker spaces. She has published at AISTech, Iron \& Steel Technology, and ASEE, and is interested in pursuing graduate studies in Materials Science \& Engineering or Engineering Education. Madeleine can be contacted at madeleine_jennings@outlook.com.

\section{Dr. Kimberly Grau Talley P.E., Texas State University}

Dr. Kimberly G. Talley is an assistant professor in the Department of Engineering Technology, Maker Space Co-Director and Senior Research Fellow for the LBJ Institute for STEM Education and Research at Texas State University, and a licensed Professional Engineer. She received her Ph.D. and M.S.E. from the University of Texas at Austin in Structural Engineering. Her undergraduate degrees in History and in Construction Engineering and Management are from North Carolina State University. Dr. Talley teaches courses in the Construction Science and Management Program, and her research focus is in student engagement and retention in engineering and engineering technology education. Contact: talley@txstate.edu

\section{Dr. Shaunna Fultz Smith, Texas State University}

Dr. Shaunna Smith is an Assistant Professor of Educational Technology in the Department of Curriculum and Instruction at Texas State University. She holds an Ed.D. in Curriculum \& Instruction with an emphasis on technology integration and art education. Her teaching and research explore how the hands-on use of design-based technologies (e.g. digital fabrication, 3D modeling and printing, computer programming, and DIY robotics) can impact multidisciplinary learning that transcends traditional content contexts (e.g. arts-based STEM integration). At her free mobile makerspace for K-12 students and teachers, The MAKE Lab (http://themakelab.wp.txstate.edu), she is currently researching how recurring experiences with these design-based technologies impact visual spatial skills, self-efficacy, and positive attitudes toward failure (e.g. persistence in the face of obstacles; reconceptualization of failure as a paradigm for creative learning) with teachers and $\mathrm{K}-12$ students. These concepts are also part of her research as Co-Director of Bobcat Made, which is the collaborative university makerspace.

\section{Dr. Araceli Martinez Ortiz, Texas State University}

Araceli Martinez Ortiz, PhD., is Research Associate Professor of Engineering Education in the College of Education at Texas State University. She leads a comprehensive research agenda related to issues of curriculum and instruction in engineering education, motivation and preparation of under served populations of students and teachers and in assessing the impact of operationalizing culturally responsive teaching in the STEM classroom. As executive director of the LBJ Institute for STEM Education and Research, she collaborates on various state and national STEM education programs and is PI on major grant initiatives through NASA MUREP and NSF Improving Undergraduate STEM Education and NSF DUE . Araceli holds Engineering degrees from The University of Michigan and Kettering University. She holds a Masters degree in Education from Michigan State and a PhD in Engineering Education from Tufts University. 


\title{
Implementing Best Practices and Facing Facilities Realities: Creation of a New University Makerspace
}

\begin{abstract}
Findings from an initiative funded as part of a collaborative NSF IUSE-funded grant, reveals research-to-practice challenges and successes related to the establishment of a new researchfocused university makerspace at Texas State University. The resulting space, Bobcat Made, was achieved in spite of space and funding challenges. It is a space under continuous improvement targeted to better reach the ideals laid forth in the best practices discoveries from this collaborative project. In addition, Bobcat Made makerspace is described in this paper and poster as well as the challenges that were faced/overcome in implementing the best practice ideals. A discussion regarding key findings related to programmatic, facilities, personnel, and online-tools will also be presented.

Makerspace design considerations include high visibility both in physical location and in online presence, welcoming environments to help new students engage in the space, the culture of the makerspace and fostering a sense of student co-ownership. Bobcat Made makerspace has attempted to implement these ideals through furnishing, signage, staff training, special theme nights to attract new users, establishment of cross-college partnerships, employment of effective marketing strategies, a website for the makerspace, organization of a base of both volunteer and part-time student workers and the establishment of a Bobcat Made twitter account, and a wide range of open-use makerspace hours.
\end{abstract}

This poster and paper will further describe the key recommendations developed by the research team and how they were implemented at Bobcat Made

\section{Introduction}

The drive to introduce a collaborative and innovative environment for students to freely create and learn has given rise lately to an influx of university makerspaces. These spaces are characterized by the presence of prototyping equipment, such as 3-D printers and laser cutters, woodworking tools, classic machining equipment, and basic hand tools. A makerspace seeks to serve as a congregation site where individuals can design, build, and create using whatever materials are at their disposal. Their purpose is to serve as an environment that encourages students to generate and share ideas, and then build and test them.

While university makerspaces are a relatively new concept, dating back to around $2001{ }^{1}$, there has been a significant amount of research into the effects of makerspaces on student design selfefficacy and student retention in Science, Technology, Engineering, and Math (STEM) related fields. There is no single ideal way to establish and maintain a makerspace at a university. However, prior research as part of this collaborative NSF-funded project has established that successful maker spaces feature a welcoming environment, a sense of accessibility and organization, the promise of a friendly social feature, and a sense of student ownership. The presence of these factors, or the lack thereof, may influence a student's motivation and anxiety about using a makerspace. This paper will seek to describe the best practices for establishing and 
maintaining a successful makerspace, as well as the implementation of these ideals in the establishment of a new university makerspace at Texas State University.

\section{Best Practices}

\section{Makerspace Environment}

A key factor contributing to a makerspace's success was a student's initial impression of the space. A wide assortment of variables within a space may play a role in first impressions. An obvious aspect of a space's environment that notably effects students is the physical arrangement and appearance of a space itself ${ }^{2,3}$. According to Penney et al., students are particularly sensitive to an environment when they are "first timers". Students in this study who were visiting a makerspace for the first time and were instructed to write notes about their visit wrote extensively about the makerspace's appearance. The language that was used to describe a makerspace in this study was overwhelmingly descriptive, describing its respective space as a "dungeon." ${ }^{3}$ Certainly this type of derogatory description is a result of feelings that the student experienced when seeing this space for the first time. Other tactics besides the redesign of the space that have been used to improve the environment have been to play music, add inviting furniture to the space, and including appropriate signage, which helps to alleviate anxiety in newcomers by providing direction ${ }^{2}$.

The impression that a student gets when first visiting a university makerspace is also dependent upon the equipment inside of the space. A well-stocked makerspace elicits excitement in students visiting for the first time and may influence a student to become a regularly attending participant ${ }^{2}$. It should be noted that an overwhelming number of makerspaces possess a 3-D printer. In fact, it is quite unusual for a university makerspace to be without one ${ }^{1,3,4,5,6,7}$. Other common capabilities for university makerspaces are laser cutters, wood and metal working capabilities, workbenches, and electrical and/or soldering equipment. It is not uncommon to see $\mathrm{CNC}$ routers and mills, CAD/CAM stations, PCB mills, plasma cutters, vinyl cutters, 3-D scanners, or welding stations ${ }^{1}$.

Additionally, it is vital that the space is well-organized. One tactic used to organize has been to split the makerspace up into functional sections. One way to go about this is section machines and equipment into prototyping, machining, and fabrication sections. Tomko et al. mentions that a particular makerspace studied had a prototyping section that comprised of 3-D printers, laser cutters, and work benches, a machining section with metalworking capabilities and 'higher-end' machinery, and a fabrication section with drills, lathes, and woodworking equipment. This gives the rooms "purpose" and prevents students from becoming overwhelmed by the makerspace when first visiting, as well as to ensure accessibility of the desired machines and materials ${ }^{2,3}$.

\section{Accessibility/Visibility of Makerspaces}

It is evident that an aspect vital to the success of a makerspace is its accessibility to its users, both inside and outside of the space itself. Tomko et al. reports that students are typically not aware of the makerspace on campus in the first place ${ }^{2}$. The easiest way to avoid this issue is to 
intentionally place the makerspace in a location central to the desired demographic of users, such as the library or the engineering building, while making sure barriers of entry, such as stairs and locked doors are not present $1,2,6,8,9$. While realizing that this is not always a possibility, increasing visibility to the makerspace by adding to the exterior display, advertising online or on social platforms, or holding hosted events at or about the makerspace is the next best option to help make the space more accessible to students who are unaware of its existence ${ }^{2,6,9}$.

There are factors inherent to the makerspace itself that affect student perception of accessibility. Notably, organization is perceived as a feature of accessibility. However, if the space was too clean or not well-used, the space was observed as inaccessible as well. Indeed, the makerspaces that are perceived as most accessible feature a tidy, yet lived-in appearance that makes students feel welcome. Spaces that appeared too bare or "industrial" had the opposite effect, and as a result, came across as inaccessible ${ }^{2,3}$.

Reportedly, students felt anxiety about entering a space and not knowing where to go or what to $\mathrm{do}^{3}$. An effective way to avoid this issue is to ensure that there is an appropriate amount of signage and accessible instruction for new attendees. This can be accomplished by way of posters on the wall, standard operating procedures, and equipment instructions or information available online or in the makerspace. Helpers and makerspace staff should be accessible, understandable, friendly, and knowledgeable as well ${ }^{2,8}$.

Other factors affecting student perceptions of accessibility are the amount of materials resources available, how intimidating the equipment appears, and if the equipment is operable ${ }^{2,4,6}$. For example, Penney et al. states that the perception of accessibility of a particular makerspace was affected when multiple students mentioned that outlets for their electronics were either inaccessible, or inoperable ${ }^{3}$. Ensuring the smooth operation of makerspace equipment is certainly a vital aspect to its success.

\section{Social Aspects of Makerspaces}

Makerspaces have gained the reputation of being a social hub where makers can share ideas and improve upon them using peer guidance, referred to as the "student-to-teacher" mechanic ", 4, 5, 6 . In order to ensure good participation, it is vital to establish and encourage a healthy social life in makerspaces so as to facilitate a welcoming and helping environment for shy students that are reluctant to become involved ${ }^{1}$.

Unsurprisingly, studies indicate that females and minorities are particularly underrepresented when it comes to makerspace involvement ${ }^{2,5,3,8}$. The most common reason given for their lack of involvement was that they felt as though they did not belong ${ }^{5,3,8}$. Providing a helping, inclusive, and safe place ensures that the social aspect of a makerspace provides a foundation for extensive involvement and encouragement for underrepresented groups, as well as everybody else ${ }^{6,8}$.

Maintaining sensitive, helpful language and dispositions is important to the success of a makerspace. According to Tomko et al., a tour guide described a machine shop to a female 
participant as "one of the 'scariest' rooms", and that it had the capacity to kill her if she was not properly supervised. This description was not given to the male participant ${ }^{2}$. Language such as this is divisive, and inevitably introduces a sense of fear and anxiety in the female participant's mind that is not present in the male's. Higher anxiety correlates to a lower likelihood of participation in the makerspace ${ }^{2}$. In the interest of retaining underrepresented demographics in makerspaces, it is imperative to recognize that these groups may already feel as though they are an imposition, and measures must be taken in a space to avoid making this impression ${ }^{3}$.

By establishing a helpful, supportive, and failure-positive environment, shy, less confident, or anxious students are certainly more apt to remain involved in their university's makerspace ${ }^{5}$.

\section{A Sense of Student Co-Ownership}

An interesting tactic that has been found to be useful in designing a makerspace is allowing the student to be at the heart of its creation. By allowing students to be integrally involved in a space's creation and maintenance, the student is given the power to build it the way that they want to see it.

By allowing students to help design their university makerspace that they were going to be using, a sense of co-ownership was established. Students involved gained entrepreneurial skills, as well as engineering skills that makerspaces are meant to teach. This allowed the students to "see the value" in the space, which helped the makerspace to become more successful ${ }^{2}$.

Staffing students in the makerspace is an effective way to help students feel a responsibility toward the space ${ }^{1}$. Additionally, by allowing students to become involved in makerspace improvement processes, their unique points of view as student users may allow for possible modes of improvement that may not have been noticed had the students not been considered coowners of the space ${ }^{6}$. Listening to student feedback and involving them from the beginning ensures good student participation and a successful makerspace ${ }^{5}$.

\section{Implementation of Best Practices at Texas State University}

\section{Environment}

At the outset of Bobcat Made's founding, the ideal has been to make this space welcoming and to include signage that can help students navigate in the space. The ideal of being welcoming gets into the topic of makerspace culture, but it is a point in the volunteer staff training that we want to be known as being very welcoming. Signage has been a key focus in this new makerspace. There are signs on the sign in/out computer, quick start guides posted by all equipment, and even a staff on duty picture board to help users identify who would be best able to answer their questions (Figure 1). Some of the furnishing choices were also made with an eye to the way they could positively influence the culture of the space, as detailed below. 


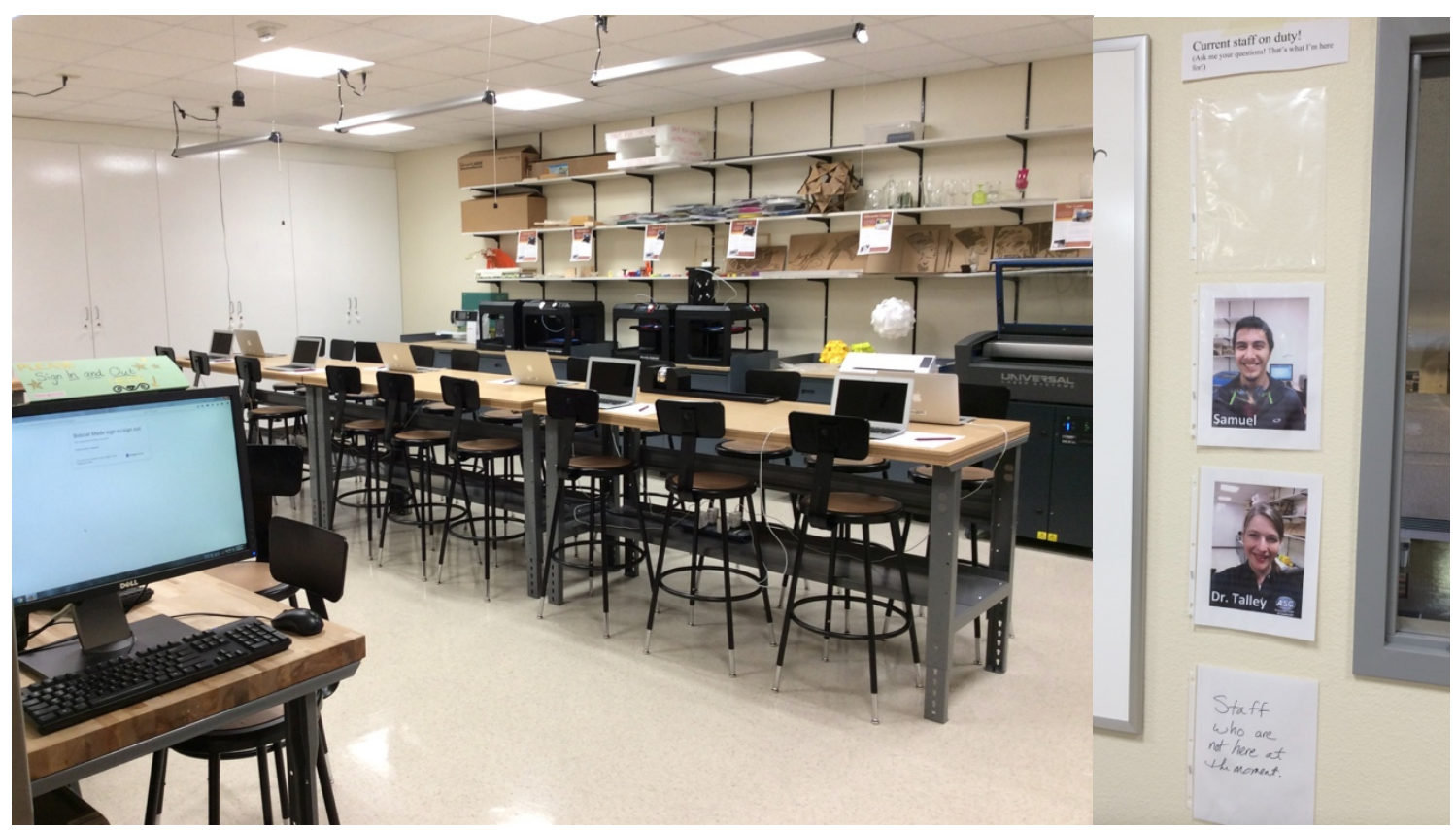

Figure 1: Signage and Communal Work Table (left) and Staff on Duty Signage (right)

\section{Accessibility/Visibility}

While the ideal arrangement for the location of a makerspace would be where students could see it every day in their normal walk to class, there was no space available in the Engineering, Engineering Technology, and Physics building at the time of this Bobcat Made's founding. Working with this constraint and in a collaboration between the Colleges of Education and of Science and Engineering, the new makerspace was located in a student services building in square footage controlled by the College of Education and with equipment from the College of Science and Engineering (COSE). While not adjacent to engineering classes, this location has drawn in many students from outside of COSE to use the makerspace. The space is small compared to other university makerspaces (600 SF), but features a variety of tools to try to appeal to range of students including the ubiquitous 3D printers, a laser engraver, an embroidery machine, three sewing machines, a vinyl cutter, and a desktop three-axis mill. The location overlooks an atrium space that contains the university's writing center, so we installed a banner to be visible to the atrium (Figure 2). 


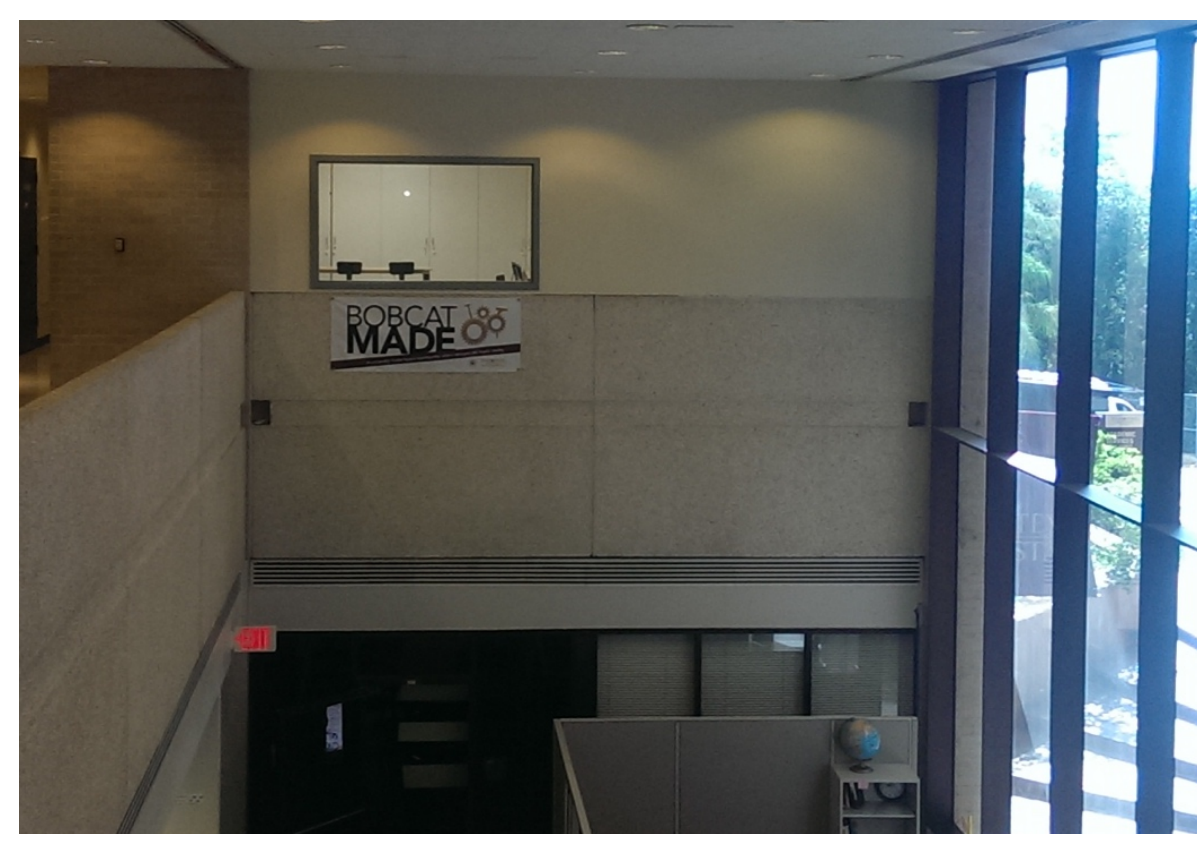

Figure 2: Banner in Atrium to Enhance Visibility

In addition to the location of the physical space, the signage mentioned above in the Environment section helps to make the space feel more accessible. It is intended to help new users demystify the makerspace without having to overcome internal resistance to asking some basic questions. Beyond the signage, the makerspace as a website to help host information about the space including training resources for the equipment and the open use hours. The initial implementation of the website was a version of the equipment quick start guides and open use flyer. With refinement, the website now contains training videos, more detailed training guides (versus the one-page quick start guides), links to free design software, updated open use hours, and the twitter feed from the makerspace's twitter account.

\section{Social Aspects/Culture}

The organization of the physical space is intended to foster collaboration. The main worktables are aligned in the middle of the room to allow for a communal sharing environment, as shown in Figures 1 and 3. If the tables had been separated there was concern that students would be less likely to feel comfortable walking up and sharing a table of six that was already occupied, but the one large table sends the visual signal that the workspace is for all. Additionally, the makerspace has a couch in order to encourage students to feel comfortable socializing in the space to try to foster community building. 


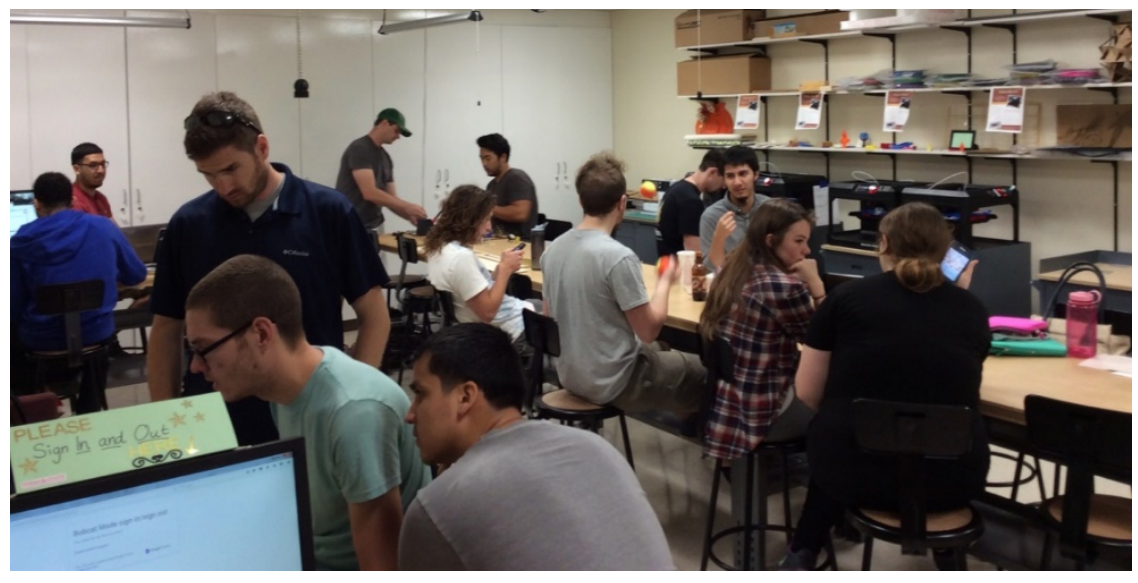

Figure 3: Student Use of the Communal Table (and computer workstations)

The culture, however, is more dominantly established by the student staff than the furnishings. At Bobcat Made, the student staff members are volunteers and therefore have a real interest in the space before coming on as staff members. Often current staff members start encouraging the most frequent users to become staff as well, which helps to populate the staff roster, but can mean any demographic (gender and race, e.g.) trends in the users are then reinforced in the staff. This grant provided some funding for student salaries to provide initial staffing of the makerspace and some of these part-time positions are being used to add more diversity to the staff in order to help encourage a diversity of users.

The student staff has also used the white board-surfaced cabinets to encourage users to share about themselves with weekly polls such as favorite song, video game, or quote (Figure 4). The staff's helpful attitudes are what set the culture of the space as the staff members are the face of the makerspace.

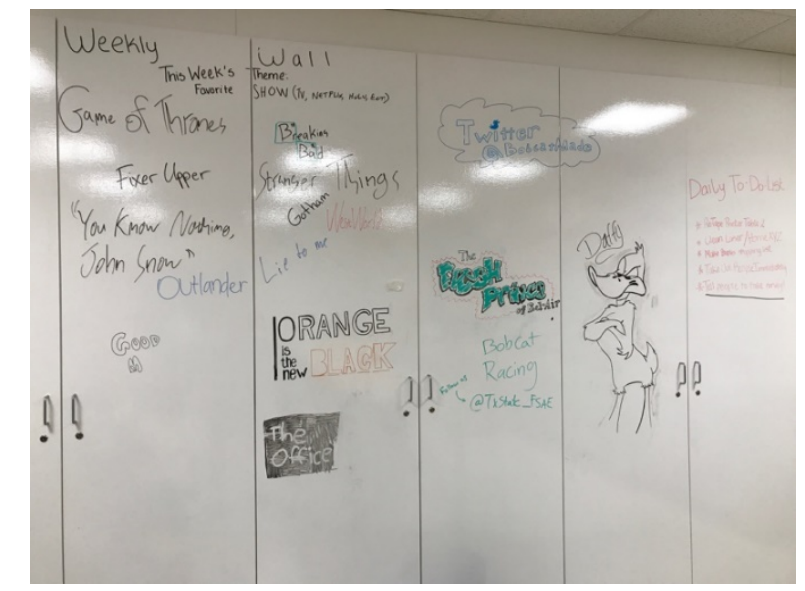

Figure 4: Staff-led User Poll on the White Board-Surfaced Cabinets

\section{Student Co-Ownership}

Student co-ownership ties back into the culture of the space. The student staff set the tone for the culture of the makerspace, and that culture includes their sense of co-ownership. The co- 
directors of Bobcat Made tried to foster this sense of co-ownership by trying to empower the students to be the leaders of the space and make some of the decisions on how to run it. One example has been requesting the student staff to make lists of materials that are needed and then trying to accommodate as many requests as possible within budgetary and logistical constraints. For instance, the student staff asked for a half a dozen USB drives to be able to loan out to users for their projects. This program has been especially popular for transferring 3D printing files from computers to the machines. The loaner USB program adds to the welcoming spirit of the makerspace, as the student staff is obviously trying to help everyone get their project to completion. The staff also started using the white board-finished cabinets to record when certain maintenance actions and chores had been completed, such as vacuuming the laser engraver honeycomb bed or taking out the recycling. Some members of the staff decided to set up a twitter feed and a hashtag for the makerspace in order to promote events and share completed projects. Another staff member, who was majoring in communications, even decided to make a promotional video for the space! These are anecdotal examples of how the students running the space have demonstrated their sense of co-ownership. The faculty overseeing the space have tried to foster this co-ownership through interactions with the students, such as requesting needed material lists, asking them to develop protocols for self-governance, and cheering on their innovations.

\section{Summary}

There are many factors that play into the success of a makerspace that are not as simple as where to place a certain piece of equipment or what color to paint the walls. Research indicates that some of the most influential aspects in a makerspace's success are its environment, how accessible students perceive it, how healthy the social aspect of the space is, and a sense of student co-ownership of the space. Many of these aspects are influenced by the makerspace staff, so care should be given to staff training.

Students are susceptible to making decisions based on first impressions, and ensuring that a makerspace features a welcoming environment, a healthy variety of tools, and operable equipment will result in a more positive experience for first-time attendees. Additionally, close attention should be paid to which resources are being used the most to ensure that resources do not run out and equipment is always in operating condition. Having a staff that is knowledgeable in what the makerspace has to offer can ensure that the space remains operable, and therefor accessible. Lastly, keep in mind that the needs of the students may change, and the makerspace needs to be prepared to adapt in order to survive ${ }^{5}$.

\section{Acknowledgements}

This work is supported by the National Science Foundation through Award No. DUE 1431721, 1432107 and 1431923. Any opinions, findings, and conclusions or recommendations expressed in this material are those of the authors and do not necessarily reflect the views of National Science Foundation. 


\section{References}

1. Barrett, T. W., \& Pizzico, M. C., \& Levy, B., \& Nagel, R. L., \& Linsey, J. S., \& Talley, K. G., \& Forest, C. R., \& Newstetter, W. C. (2015, June), A Review of University Maker Spaces, Proceedings from 2015 ASEE Annual Conference \& Exposition, Seattle, Washington. 10.18260/p.23442

2. Tomko, M., \& Nagel, R. L., \& Aleman, M. W., \& Newstetter, W. C., \& Linsey, J. S. (2017, June), Toward Understanding the Design Self-Efficacy Impact of Makerspaces and Access Limitations, Proceedings from 2017 ASEE Annual Conference \& Exposition, Columbus, Ohio. https://peer.asee.org/27761

3. Penney, M. F., \& Watkins, J. D., \& Levy, B., \& Linsey, J. S., \& Nagel, R. L., \& Newstetter, W. C., \& Talley, K. G., \& Smith, S. F. (2016, June), 'Making' an Impact: An Ethnographic Approach to University Maker Spaces, Proceedings from 2016 ASEE Annual Conference \& Exposition, New Orleans, Louisiana. 10.18260/p.26226

4. Tomko, M., \& Hilton, E., \& Forest, C., \& Talley, K. G., \& Smith, S., \& Nagel, R., \& Linsey, J. (2017, June), Observations on Guiding Principles, or Best Practices, in University Makerspace, Proceedings from 2017 ASEE Annual Conference \& Exposition, Columbus, Ohio.

5. Morocz, R. J., \& Levy, B., \& Forest, C., \& Nagel, R. L., \& Newstetter, W. C., \& Talley, K. G., \& Linsey, J. S. (2016, June), Relating Student Participation in University Maker Spaces to their Engineering Design Self-Efficacy, Proceedings from 2016 ASEE Annual Conference \& Exposition, New Orleans, Louisiana. 10.18260/p.26070

6. Levy, B., \& Morocz, R. J., \& Forest, C., \& Nagel, R. L., \& Newstetter, W. C., \& Talley, K. G., \& Smith, S. F., \& Linsey, J. S. (2016, June), MAKER: How to Make a University Maker Space, Proceedings from 2016 ASEE Annual Conference \& Exposition, New Orleans, Louisiana. 10.18260/p.25623

7. Nagel, R., \& Talley, K. G. (2014, November 11), Conference Call.

8. Linsey, J., \& Forest, C., \& Nagel, R., \& Newstetter, W., \& Talley, K. G., \& Smith, S. (2016, June), Understanding the Impact in University Makerspaces, Proceedings from 2016 ASEE Annual Conference \& Exposition, New Orleans, Louisiana.

9. Nagel, R., \& Linsey, J., \& Talley, K. G. (2016, July 12), Conference Call. 